\title{
Bio-enrichment of oilseed cakes by Mortierella alpina under solid-state fermentation
}

\author{
Marta Ferreira $^{\text {a }}$, Helena Fernandes ${ }^{\text {b,c }}$, Helena Peres ${ }^{\text {b, }}$, Aires Oliva-Teles ${ }^{\text {b,c }}$, Isabel Belo ${ }^{\text {a }}$, José \\ Manuel Salgado a,b,* \\ ${ }^{\text {a }}$ Centre of Biological Engineering, University of Minho, Campus de Gualtar, 4710-057, Braga, Portugal \\ ${ }^{\mathrm{b}}$ CIMAR/CIIMAR - Centro Interdisciplinar de Investigação Marinha e Ambiental, Universidade do Porto, Terminal de Cruzeiros do Porto de Leixões, Av. General Norton \\ de Matos, 4450-208, Matosinhos, Portugal \\ ${ }^{\mathrm{c}}$ Departamento de Biologia, Faculdade de Ciências, Universidade do Porto, Rua do Campo Alegre, Edifício FC4, 4169-007, Porto, Portugal
}

\section{A R T I C L E I N F O}

\section{Keywords:}

Polyunsaturated fatty acids

Agro-industrial waste

Linseed oil

$\alpha$-linolenic acid

\begin{abstract}
A B S T R A C T
Oilseed cakes have potential for new applications as substrates for solid-state fermentation (SSF), to increase their nutritional value by increasing its polyunsaturated fatty acids (PUFAs) or protein content. In this sense, it was performed a screening of oilseed cakes to be used as substrates for the production of PUFAs by Mortierella alpina Peyronel MUM 9412. Of all by-products tested, linseed cake (LSC) was the oilseed cake that achieved the highest production of total PUFAs: $153.09 \pm 2.25 \mathrm{mg} / \mathrm{g}$. Overall, the PUFAs and protein contents of fermented LSC increased 33\% and 11\%, respectively. Further, supplementation of the rapeseed cake with linseed oil, prior to the SSF, proved to increase the PUFAs production in about $26 \%$.

This study demonstrated the potential of SSF for improving linseed and linseed cakes nutritional composition and the positive effect of linseed oil as inductor to improve the PUFAs production by M. alpina.
\end{abstract}

\section{Introduction}

Polyunsaturated fatty acids (PUFAs) belonging to the $\omega-3$ class such as eicosapentaenoic acid (EPA), $\alpha$-linolenic acid (ALA) and docosahexaenoic acid (DHA) and to the $\omega-6$ class, like arachidonic acid (ARA), $\boldsymbol{\gamma}$ linoleic acid (GLA) and linoleic acid (LA), have essential structural and functional roles in higher organisms, including humans. They are present in high quantities in the cerebral cortex, retina (Fontani et al., 2005), immunocompetent cells (Simopoulos, 1999) and membrane phospholipids (Sakuradani et al., 2009). In humans, LA and ALA can be converted into long-chain PUFAs (LC-PUFA), although this conversion occurs at extremely low rates and, therefore, an external input of these LC-PUFAs (EPA; DHA; ARA) is necessary (Bellou et al., 2016). Most of LC-PUFAs are obtained from fish oils (Cantrell \& Walker, 2009; Dyal \& Narine, 2005). The production of purified sources of DHA and EPA, obtained from fish oil, possess several limitations including the risk of contamination with heavy metals and organic pollutants ( $\mathrm{Li} \& \mathrm{Hu}$, 2009); undesirable flavor, taste and odor; stability problems; and high price of extraction and purification of fish oil PUFAs from fish oil (Abedi \& Sahari, 2014). PUFAs can be obtained from the seeds of oleaginous plants, but plants do not produce LC-PUFA without genetic manipulation (Ratledge, 2004). In the last two decades, new alternative sources of PUFAs have been commercially explored using microorganisms, including fungi, bacteria and algae (Aita et al., 2018).

Oilseed cakes are the solid by-products obtained after extraction of oils from the seeds (Ramachandran et al., 2007). According to FAO (2018), the world production of oilseed cakes was 152 million tons in 2017 and is expected to increase about $3.5 \%$ in $2018 / 2019$. The quality of the seeds or nuts, the oil extraction method and the storage conditions affect the nutritional value of oilseed cakes (Ramachandran et al., 2007). Usually, the oilseed by-products are used as animal feedstuffs or as soil fertilizers (Ramachandran et al., 2007; Teh \& Bekhit, 2015).

Oilseed cakes generally have a high protein, lipids, carbohydrates, and mineral content (Teh \& Bekhit, 2015). Among oilseed cakes, the linseed cake (LSC), a by-product of the oil extraction process from Linum usitatissimum seeds, has about $15-20 \%$ protein, $7 \%$ lipids and $10 \%$ crude fiber (Gutiérrez et al., 2010). Linseed oil is a good source of $\omega-3$ PUFAs, particularly $\alpha$-linoleic acid (ALA), which amounts to $50-70 \%$ of the total lipids. LSC can be used as a source of protein and lipids in animal diets (Ahmad et al. 2017). Sunflower cake (SFC) has protein and crude fiber

\footnotetext{
* Corresponding author. Centre of Biological Engineering, University of Minho, Campus de Gualtar, 4710-057, Braga, Portugal.

E-mail address: jmsalgado@ceb.uminho.pt (J.M. Salgado).
} 
contents ranging between $20-45 \%$ and $17-25 \%$, respectively (Pedroche, 2015) and also has a residual oil content (around 3-5\%) (Moura et al., 2015; Pedroche, 2015). Soybean cake (SBC) contains about 40-49\% crude protein, $3-8 \%$ of fiber and residual oil levels around $1-3 \%$, rich in oleic and linoleic acids (Ivanov et al., 2010). Rapeseed cake (RSC) contains $28-32 \%$ protein, $10-12 \%$ of fiber and $9-16 \%$ of oil, depending on the efficiency of oil extraction (Banaszkiewicz, 2011), and is rich in oleic acid (Kaczmarek et al., 2017).

Solid-State Fermentation (SSF) is a fermentation process that occurs in the absence or near absence of free water, where the solid matrix may be used as carbon source for the microorganisms (Thomas et al., 2013). Several wastes were used to produce value-added compounds trough SSF such as citric acid (Lu et al., 1998), cellulase, xylanase, $\beta$-glucosidase (Leite et al., 2016) and PUFAs (Aita et al., 2018; Jang et al., 2000).

Oleaginous microorganisms that can accumulate up to $80 \%$ of their biomass as lipids are recognized as a good alternative to PUFAs production due to their capacity to produce, absorb and transform exogenous fatty acids (Béligon et al., 2016; Cantrell \& Walker, 2009). Several microorganisms have already been used to produce PUFAs, such as mycobacteria (Mycobacterium phlei and $M$. smegmatis) and fungi, such as Cunninghamella elegans (Conti et al., 2001) and M. alpina (Jang et al., 2000). Fungi have some particularities that made them a potentially good source of PUFAs since they accumulate a high concentration of lipids with a certain fatty acid profile that may be modulated by the manipulation of the growth medium (Dyal \& Narine, 2005; Mamani et al., 2019). Also, oleaginous fungi can produce PUFAs through SSF in a low-cost fermentation medium, such as agro-industrial wastes or industrial by-products (Béligon et al., 2016). In fact, several studies demonstrated the potential of SSF with $M$. alpina to produce PUFAs (Jang et al., 2000; Jang \& Yang, 2008; Mamani et al., 2019; Stressler et al., 2013). Importantly, $M$. alpina has been granted the generally recognized as safe (GRAS) status by the Food and Drug Administration (FDA) (Mamani et al., 2019).

The supplementation of SSF substrates with inducers, precursors and additives may modulate the fungus metabolism towards the increase of lipid level and, additionally, influence the composition of the final product (Koritala et al., 1987). In order to increase the $\omega-3$ LC-PUFA production on substrates by oleaginous microorganisms, an oil-rich in $\omega$-3 PUFA precursor can be added to the substrate before fermentation (Dyal \& Narine, 2005; Jang et al., 2000).

The aim of the present work was to bioprocess oil cakes, RSC, SFC, SBC and LSC, by SSF using M. alpina to improve the protein, lipids and LC-PUFAs contents. In addition, a new strategy to improve the fatty acid profile of linseed oil by SSF of the whole-linseed was also studied. On the other hand, the addition of linseed oil to RSC, SFC and SBC as an inductor of PUFAs production was also tested. Finally, the principal components analysis (PCA) was performed to evaluate the effect of all substrates used in SSF on fungal biomass, lipids, PUFAs and protein production.

\section{Materials and methods}

\subsection{Raw material}

During this work, four oilseed cakes were used: rapeseed cake (RSC), sunflower cake (SFC), soybean cake (SBC) and linseed cake (LSC). Further, whole-linseed (LS) and linseed oil (LSO) were also tested as substrates in SSF. RSC and SBC were obtained from industries in Lisbon and SFC from an industry located in the North Region of Portugal during the season 2018-2019. LS and LSC were collected from an industry in Lisbon (Portugal) and the LSO was supplied from an industry in the south of France. The particle size of oilseed cakes was less than $1 \mathrm{~mm}$, except to LS that was milled to reduce its size particle. The solids were dried by milder conditions at $55{ }^{\circ} \mathrm{C}$ for $48 \mathrm{~h}$ in an oven lab without illumination to avoid PUFAs degradation and, thereafter, they were stored in plastic bags at room temperature $\left(22-25{ }^{\circ} \mathrm{C}\right)$ without illumination and humidity.

\subsection{Fungus and inoculum preparation}

M. alpina Peyronel (MUM 9412) was obtained from MUM (Micoteca of University of Minho, Braga, Portugal) and it was preserved in glycerol stocks at $-80^{\circ} \mathrm{C}$. Then, it was revived on potato dextrose agar (PDA). During the experimental period, the fungus was preserved at $4{ }^{\circ} \mathrm{C}$ and cultured monthly on fresh PDA plates. To obtain the inoculum for SSF, the fungus was incubated on PDA at $25^{\circ} \mathrm{C}$ for 6 days.

\subsection{Solid-state fermentation}

SSF was carried out in $500 \mathrm{ml}$ Erlenmeyer flasks with $10 \mathrm{~g}$ of the dried solid substrate (RSC, SFC, SBC, LSC and LS) and the moisture level was adjusted to $75 \%$ (wet basis) with distilled water (Fernandes et al., 2019). The Erlenmeyer flasks with solid medium were sterilized at 121 ${ }^{\circ} \mathrm{C}$ for $15 \mathrm{~min}$. Then, the flasks were inoculated with half mycelium grown in a petri dish with PDA (15 mg of fungus mycelium) and incubated at $25{ }^{\circ} \mathrm{C}$ for 3 days, followed by 4 days at $16^{\circ} \mathrm{C}$. During the incubation period, the Erlenmeyer flasks were shaken once a day. Cultivations were made in duplicate. After each SSF, the fermented solid was placed in a tray and dried at $55{ }^{\circ} \mathrm{C}(24 \mathrm{~h})$. A control experiment without fungi inoculation was performed for each sterilized solid.

A study of supplementation of SFC, SBC and RSC with 10\% LSO (w/ v) before the SSF was also performed. In this study, mineral salts $\left(4 \mathrm{gl}^{-1}\right.$ $\mathrm{K}_{2} \mathrm{HPO}_{4}$, Merck; $0.5 \mathrm{~g} \mathrm{l}^{-1} \mathrm{MgSO}_{4} \cdot 7 \mathrm{H}_{2} \mathrm{O}$, Panreac; and $0.1 \mathrm{~g} \mathrm{l}^{-1} \mathrm{CaCl}_{2}$. $2 \mathrm{H}_{2} \mathrm{O}$, Panreac) and commercial LSO $10 \%(\mathrm{w} / \mathrm{v})$ were added to the fermentation flasks containing the cakes.

\subsection{Quantification of fungal biomass}

Ergosterol is a primary sterol present in the filamentous fungi cell membranes and was used as an indirect method to evaluate fungal growth (Fernandes et al., 2019). For that purpose, $1 \mathrm{~g}$ of sample (in duplicate) was mixed with $20 \mathrm{ml}$ of potassium hydroxide (10\%) solution in methanol and the solution was stirred for $20 \mathrm{~min}$. Then, $10 \mathrm{ml}$ of the solution were removed to a cup and heated at $55-60^{\circ} \mathrm{C}$ for $20 \mathrm{~min}$. After cooling, $3 \mathrm{ml}$ of distilled water and $2 \mathrm{ml}$ of hexane were added and the solution was vortexed for $1 \mathrm{~min}$, obtaining two phases. The upper phase (hexane) was removed to another tube and the hexane extraction was performed two more times for each sample. The tubes with samples were placed in contact with a nitrogen source to evaporate the hexane. After evaporation, $2 \mathrm{ml}$ of methanol was added and the samples were transferred to $1.5 \mathrm{ml}$ amber glass vials to be analyzed by HPLC. Ergosterol was determined using an HPLC Varian equipped by autosampler (Basic-Marathon, Spark), isocratic pump (Varian 9002) and UV detector (Varian ProStar). The column was a reverse phase-C18 (Waters Spherisorb ODS2, $4.6 \times 250 \mathrm{~mm}$ ). The mobile phase was methanol at a flow rate of $1 \mathrm{ml} \mathrm{min}-1$ and detection was made at $282 \mathrm{~nm}$.

\subsection{Lipids extraction}

For lipid extraction the method proposed by Araujo et al. (2008) was used with some alterations. A mixture of $0.4 \mathrm{~g}$ of sample, $1.6 \mathrm{ml}$ of distilled water, $4 \mathrm{ml}$ of chloroform and $2 \mathrm{ml}$ of methanol was stirred for $1 \mathrm{~h}$. Then, the mixture was passed through a Pasteur pipette with glass wool. The flasks were washed with $2 \mathrm{ml}$ of chloroform and $2 \mathrm{ml}$ of distilled water and the mixture was also passed through the same Pasteur pipette. Thereafter, the glass wool was washed with $2 \mathrm{ml}$ of chloroform and the different phases allowed to rest on a separating funnel. The lower phase (chloroform with lipids) was recovered and the chloroform was evaporated using nitrogen injection. The difference in weight between the empty flask and the flask after evaporation of chloroform corresponds to the lipids mass. 


\subsection{Fatty acid and protein determination}

The fatty acid methyl esters (FAMES) production were developed following the method proposed by Araujo et al. (2008) with some changes. The extracted lipids were dissolved in $1 \mathrm{ml}$ of $0.5 \mathrm{~m} \mathrm{l}^{-1}$ $\mathrm{KOH}-\mathrm{MeOH}$ solution, vortex-mixed and heated for $10 \mathrm{~min}$ at $40{ }^{\circ} \mathrm{C}$. A $100 \mu \mathrm{l}$ of a solution with $1 \mathrm{~g} \mathrm{l}^{-1}$ pentadecanoic acid was added to each sample as an internal standard. After cooling the mixture in water, $2 \mathrm{ml}$ of $\mathrm{BF}_{3} / \mathrm{CH}_{3} \mathrm{OH}(14 \%)$ was added, vortex-mixed and heated for $10 \mathrm{~min}$ at $40{ }^{\circ} \mathrm{C}$. The mixture was cooled and subsequent portions of $1 \mathrm{ml}$ of hexane and $2 \mathrm{ml}$ of water were added, vortex-mixed for $15 \mathrm{~s}$, placed in a centrifuge, allowed to reach a speed of $3000 \mathrm{rpm}$ and then stopped immediately. After collecting the hexane phase $(1 \mathrm{ml})$, an additional aliquot of $1 \mathrm{ml}$ of hexane was added to the mixture, vortex-mixed and centrifuged. After that, the hexane phase was collected to analyse FAMEs by gas chromatography (GC). The analysis was carried out in a GC system (VARIAN 3800) equipped with a flame ionization detector (FID). FAMEs were separated using a TRB-WAX $30 \mathrm{~m}$ x $0.25 \mathrm{~mm} \times 0.25$ $\mu \mathrm{m}$ column (TR140232, Teknokroma, Tr-wax), with helium as the carrier gas at $1.0 \mathrm{ml} \mathrm{min}^{-1}$. The airflow was set at $250 \mathrm{ml} \mathrm{min}^{-1}$ and the nitrogen and hydrogen flow of $30 \mathrm{ml} \mathrm{min}{ }^{-1}$. The temperatures of the injection port and detector were 250 and $280{ }^{\circ} \mathrm{C}$, respectively. The initial oven temperature was $40^{\circ} \mathrm{C}$ for $2 \mathrm{~min}$, with a $30{ }^{\circ} \mathrm{C} / \mathrm{min}$ ramp to $150{ }^{\circ} \mathrm{C}$ and a $3{ }^{\circ} \mathrm{C} / \mathrm{min}$ final ramp to $250^{\circ} \mathrm{C}$. The calibration curves of standards were performed with commercial polyunsaturated fatty acids following the derivation process described above. The standards of polyunsaturated fatty acids were arachidonic acid (Sigma-Aldrich), $\gamma$-linolenic acid (Sigma-Aldrich), eicosapentanoic acid (Supelco), docosahexaenoic acid (Sigma-Aldrich), linolenic acid (Sigma-Aldrich), eicosatrienoic acid (Supelco) and $\alpha$-linolenic acid (Supelco).

The crude protein content $(\mathrm{N} \times 6.25)$ was determined by the Kjeldahl method after digestion with sulphur acid ( $>95 \%$ ) using a Kjeltec system (Foss 8400).

\subsection{Statistical analysis}

Results are presented as mean \pm standard deviation (SD) of two replicates. Statistical analysis was performed by $t$-test, using the probability of 0.05 for rejection of the null hypothesis. Significant differences between groups were determined by the Tukey's multiple range test. Principal components analyses (PCA) were conducted to determine how substrates affected total lipids, PUFAs, protein, and fungal biomass. Statistical analyses were performed using Statgraphics Centurion XVI.II software.

\section{Results and discussion}

\subsection{Screening of oilseed cakes for SSF with M. alpina}

\subsubsection{Fungal biomass, total lipids and protein accumulation}

Several oilseed cakes (RSC, SFC, SBC, and LSC) were inoculated with M. alpina. The fungal growth in oilseed cakes was measured by the increase of ergosterol, which is a cell membrane component present in fungi (Yang et al., 2015). The highest increase of ergosterol content of $124.6 \pm 1 \mu \mathrm{g} / \mathrm{g}$ dry solid, after 7 days of SSF, was obtained in fermented SFC, followed by fermented LSC ( $88 \pm 9 \mu \mathrm{g} / \mathrm{g} \mathrm{ds}$ ) (Fig. 1). Lower values were observed in RSC ( $51 \pm 9 \mu \mathrm{g} / \mathrm{g}$ ds) and SBC ( $54 \pm 4 \mu \mathrm{g} / \mathrm{g} \mathrm{ds}$ ) (Fig. 1). The suitability of using SFC as substrate for SSF was previously reported for filamentous fungi (Jacobs et al., 2010), yeasts mixing SFC with other co-substrate (Jiménez-Peñalver et al., 2016) and bacteria (Salim et al., 2017).

Regarding lipids content (Fig. 2a), Results showed that SSF of LSC significantly increased the lipids content by $49.9 \%$. For the other oilseed cakes, there were no significant differences $(\mathrm{p}<0.05)$ between unfermented and fermented solids. M. alpina has the ability to biosynthesize and accumulate lipids in the endoplasmic reticulum in droplets form,

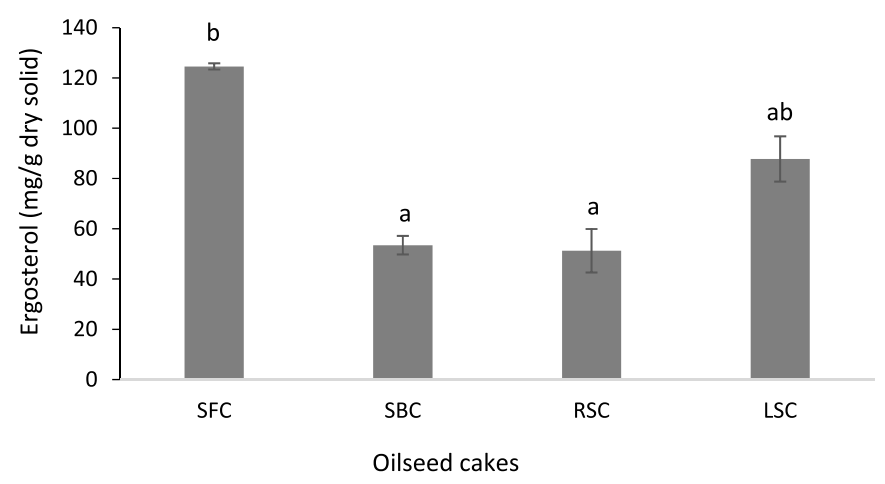

Fig. 1. Fungal biomass estimation by ergosterol content ( $\mu$ g ergosterol/g dry solid) after 7 days of SSF by M. alpina of the oilseed cakes (sunflower cake, SFC; soybean cake, SBC; rapeseed cake, RSC; and linseed cake, LSC). The Results represent the average of two independent experiments and error bars represent the standard deviation (SD). Different letters above each bar indicate a significant difference among the oilseed cake (Tukey's test; $\mathrm{P}<0.05$ ).
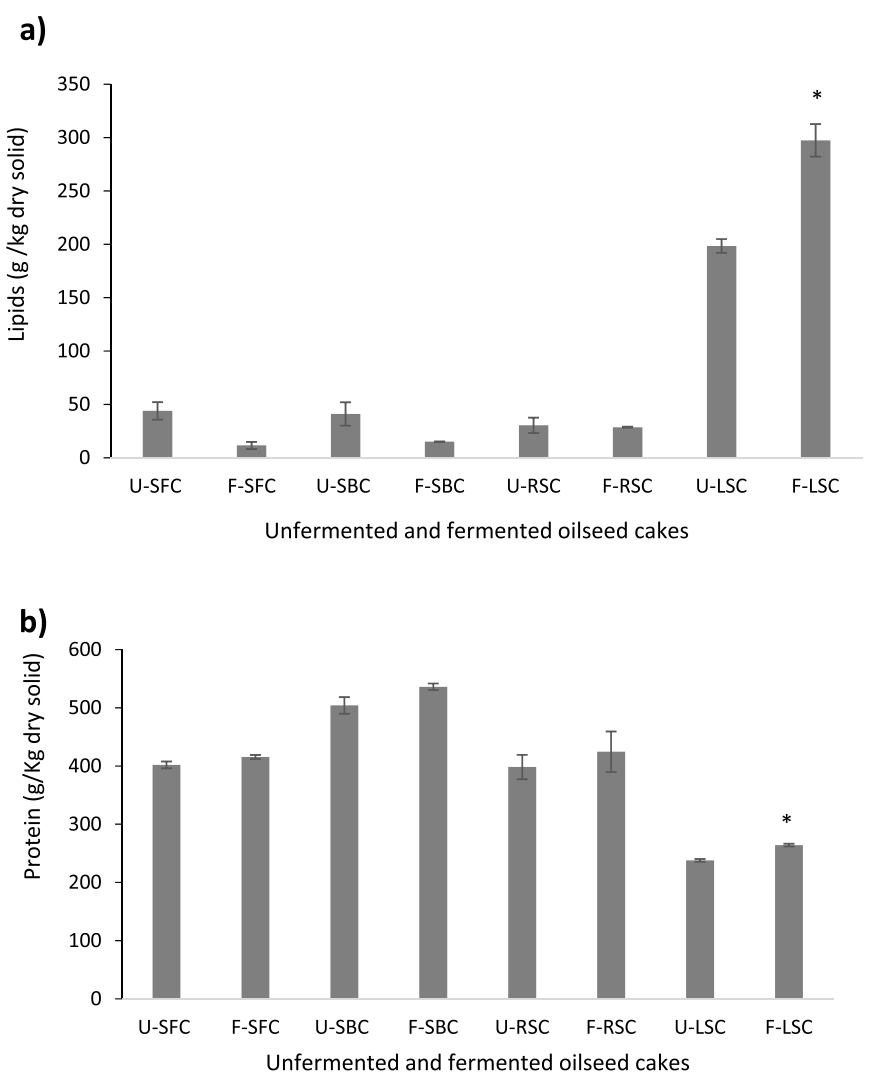

Fig. 2. Lipids (a) and protein (b) content of unfermented (U) and fermented (F) substrates (sunflower cake, SFC; soybean cake, SBC; rapeseed cake, RSC; and linseed cake, LSC) by M. alpina. The Results represent the average of two independent experiments and error bars represent standard deviation (SD). *denotes significant differences between unfermented and fermented solid (Tukey's test; $\mathrm{P}<0.05$ ).

reaching up to 50\% of its biomass (Singh \& Ward, 1997; Yu et al., 2016). Compared to another Mortierella species, Zhang and Hu (2012) observed that the SSF of soybean hull by $M$. isabellina increased the lipid content in about $33.4 \mathrm{mg} / \mathrm{g}$ of fermented product, while in the present work the SSF of LSC with M. alpina increased the lipid content in about $99 \mathrm{mg} / \mathrm{g}$ of fermented solid. Lipids content increase of $24.6 \%$ of chokeberry pomace by SSF was previously reported for other fungal genus, such as A. niger (Dulf et al., 2018). 
Comparing the oil cakes, it was observed that the highest lipid production was achieved using LSC as substrate. This result may be attributed, at least in part, to the higher lipid content of LSC than that of the other oilseed cakes tested, ensuring that there was no limitation of $\mathrm{C}$ and lipids sources for SSF, which acted as an inductor for M. alpina growth. Indeed, for the other oil cakes, it was observed that lipid content slightly decreased during SSF, suggesting that $M$. alpina used lipids as energy source for growth, owing to a carbon limitation in the growth medium (Dyal \& Narine, 2005). Similarly, Jacobs et al. (2010) used several Mortierella isolates to carry out SSF of sunflower press cake and verified that lipids content in the fermented solid was lower than in the unfermented one.

Due to the economic importance of protein sources for animal feed, the use of microorganisms to increase the protein content of feedstuffs is a suitable strategy. Throughout the SSF of LSC, the protein content increased by $11.1 \%$, while when the other oil cakes were used as substrates the protein content was not affected. Interestingly, in this case, using the LSC in SSF, M. alpina increased both protein and lipids content (Fig. 2b), suggesting the use of non-proteic C sources for M. alpina growth.

\subsubsection{PUFAs production}

As for lipids, PUFAs content increased by $32.8 \%$ (34.9\% for LA, $31.4 \%$ for ALA, $33.9 \%$ for DHA) in the SSF of LSC, while for the other substrates the PUFAs content was not affected by SSF (Table 1). In another study with M. alpina, SSF of rice bran supplemented with yeast extract and mineral salts achieved $55.9 \mathrm{mg}$ of total PUFAs/g dry solid (Jang \& Yang, 2008), being LA ( $\omega-6)$ the main PUFA (51.5 mg LA/g dry solid). In the present study, the SSF of LSC by M. alpina increased the total PUFAs content to $37.8 \mathrm{mg}$ PUFAs/g dry solid without nutrients supplementation. LA( $\omega-6)$ and ALA $(\omega-3)$ were the PUFAs produced in highest quantity: $15.7 \mathrm{mg}$ and $21.9 \mathrm{mg} / \mathrm{g}$ dry solid, respectively. In the present study, the production of ALA $(\omega-3)$ by $M$. alpina using SSF of LSC was higher than that obtained by SSF of rice bran supplemented with nutrients (2.2 mg ALA/g dry solid) (Jang \& Yang, 2008) and SSF of soybean meal mixed with distiller's dried grains with solubles $(7.5 \mathrm{mg}$ ALA) (S. Yang \& Zhang, 2016). ALA( $\omega-3)$ is a precursor of eicosanoids and is a structural component of phospholipids membranes, being an essential PUFA for humans (Ochsenreither et al., 2016).

Table 1

PUFAs content of sunflower cake (SFC), soybean cake (SBC), rapeseed cake (RSC) and linseed cake (LSC) before and after SSF M. alpina (mg PUFA/g dry solid).

\begin{tabular}{llllll}
\hline Substrate & LA & GLA & ALA & DHA & $\begin{array}{l}\text { Total } \\
\text { PUFAs }\end{array}$ \\
\hline U-SFC & $4.3 \pm$ & $0.070 \pm$ & $0.037 \pm$ & $\mathrm{ND}$ & $4.9 \pm 0.4$ \\
& 0.3 & 0.001 & 0.001 & & \\
F-SFC & $2.2 \pm$ & $0.051 \pm$ & ND* & ND & $2.3 \pm 0.4^{*}$ \\
& $0.4^{*}$ & $0.004^{*}$ & & & \\
U-SBC & $2.1 \pm$ & $0.27 \pm 0.02$ & $0.035 \pm$ & $\mathrm{ND}$ & $2.4 \pm 0.2$ \\
& 0.2 & & 0.001 & & \\
F-SBC & $0.7 \pm$ & $0.10 \pm 0.03^{*}$ & $0.034 \pm$ & $\mathrm{ND}$ & $0.9 \pm 0.3^{*}$ \\
& $0.2^{*}$ & & 0.002 & & \\
U-RSC & $5 \pm 2$ & $1.3 \pm 0.31$ & $\mathrm{ND}$ & $\mathrm{ND}$ & $7 \pm 2$ \\
F-RSC & $1.2 \pm$ & $0.15 \pm 0.07^{*}$ & $0.006 \pm$ & $\mathrm{ND}$ & $1.3 \pm 0.5^{*}$ \\
& 0.4 & & 0.001 & & \\
U-LSC & $44 \pm 4$ & $\mathrm{ND}$ & $70 \pm 5$ & $\mathrm{ND}$ & $115 \pm 10$ \\
F-LSC & $60 \pm 1^{*}$ & $\mathrm{ND}$ & $92 \pm 1^{*}$ & $0.52 \pm$ & $153 \pm 2^{*}$ \\
& & & & $0.04^{*}$ &
\end{tabular}

Mean \pm SD. $\mathrm{n}=2 . *$ indicate significant differences between unfermented and fermented solid (Tukey's test; $\mathrm{P}<0.05)$.

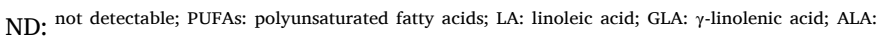
$\alpha$-linolenic acid; DHA: docosahexaenoic acid; SFC: sunflower cake; SBC: soybean cake; RSC: rapeseed cake; LSC: linseed cake, U: unfermented; F: fermented.
3.2. SSF of whole-linseed by M. alpina as a new strategy to increase its nutritional value

PUFAs of the $\omega-6$ and $\omega-3$ play an important role in human and animal feed. Particularly, in aquaculture the development of new and alternative sources rather than fish oil is of crucial importance due to sustainable and economic issues. The use of SSF as a biotechnological process to obtain traditional dietary supplements has been already used, as for example the SSF of rice or soy with Aspergillus niger in Asian countries (Sheih et al., 2014). In present study, a new strategy to obtain linseed with higher PUFAs content was tested. This strategy consisted of using the whole-linseed directly as substrate for SSF by M. alpina and then extract the lipids from the fermented product.

The ergosterol content of the whole-linseed, after 7 days of SSF with M. alpina, was $71 \pm 8 \mu \mathrm{g} / \mathrm{g}$ of dry solid, indicating that the fungus growth was not much different from that previously observed in the SSF of LSC ( $88 \pm 9 \mu \mathrm{g} / \mathrm{g} \mathrm{ds}$ ). Comparing the lipid content of the unfermented and fermented whole-linseed, it was observed that lipid content increased by $37.6 \%$ during the SSF (Fig. 3), indicating that SSF is an effective environmentally friendly process to increase the lipids yield of the whole-linseed. Moreover, the SSF of whole-linseed also enriched the protein content by $17.4 \%$, being higher than what was observed in the SSF of LSC (11.1\%). The protein content of both whole-linseed and LSC after SSF was similar and, as the protein content of whole-linseed was lower than that of LSC, the SSF of the whole-linseed could be a suitable strategy to improve its protein content.

Table 2 presents the PUFAs content of the unfermented and fermented whole-linseed. After SSF by M. alpina, the PUFAs increase was not significant except to DHA. Fungi can desaturate oleic acid by the $\Delta 12$ desaturase to produce LA, which can be biotransformed to ALA by the $\Delta 15$ desaturase using low temperatures (Certik \& Shimizu, 1999). ALA can be desaturated to EPA and DHA by the $\Delta 6$ and $\Delta 5$ desaturases (Certik \& Shimizu, 1999). Indeed, it was observed in the present study the production of DHA by SSF of whole-linseed. LA can be desaturated to $\gamma$-linolenic acid (GLA) by the $\Delta 6$ desaturase (Certik \& Shimizu, 1999). However, no GLA was detected after SSF. It is known that $\Delta 6$ desaturase may be inhibited in the presence of phenolic compounds which can explain the lack of GLA synthesis (Certik \& Shimizu, 1999).

\subsection{Effect of supplementation of oilseed cakes with linseed oil on biomass, lipids and PUFAs accumulation}

Since the SSF of whole linseed and LSC led to the highest lipid production and, more specifically, to important PUFAs synthesis, it was decided to deepen the study regarding the effect of the supplementation of other oilseed cakes with linseed oil as inductor of lipids and PUFAs production. Regarding M. alpina growth, it was observed that SSF of SFC

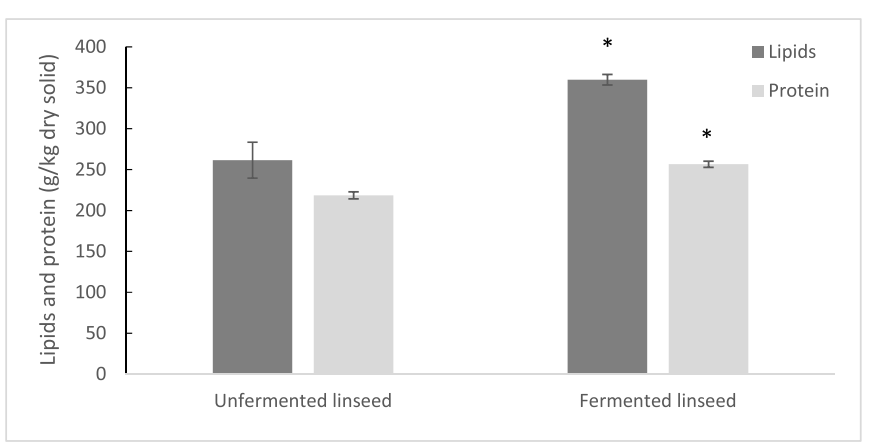

Fig. 3. Lipids (a) and protein (b) content of unfermented (U) and fermented (F) linseed meal (LSM) by M. alpina. The Results represent the average of two independent experiments and error bars represent the standard deviation (SD). * denotes significant differences between unfermented and fermented solid (Tukey's test; $\mathrm{P}<0.05$ ). 
Table 2

PUFAs in whole-linseed, before and after the SSF with $M$. alpina (mg PUFA/g dry solid).

\begin{tabular}{llllll}
\hline Substrate & LA & GLA & ALA & DHA & Total PUFAs \\
\hline U-whole linseed & $44 \pm 8$ & ND & $93 \pm 15$ & ND & $137 \pm 22$ \\
F-whole linseed & $54 \pm 5$ & ND & $109 \pm 16$ & $0.66 \pm 0.06^{*}$ & $164 \pm 20$ \\
\hline
\end{tabular}

Mean \pm SD. $\mathrm{n}=2 . *$ indicate significant differences between unfermented and fermented solid (Tukey's test; P<0.05). ND: not detectable; PUFAs: polyunsaturated fatty acids; LA: linoleic acid; GLA: $\gamma$-linolenic acid; ALA: $\alpha$-linolenic acid; DHA: docosahexaenoic acid, U: unfermented; F: fermented.

enriched with linseed oil produced the highest quantity of ergosterol ( $323 \pm 36 \mu \mathrm{g} / \mathrm{g} \mathrm{ds})$, followed by SBC (166 $\pm 10 \mu \mathrm{g} / \mathrm{g} \mathrm{ds})$ and RSC (195 \pm $8 \mu \mathrm{g} / \mathrm{g} \mathrm{ds}$ ) (Fig. 4). Comparing the quantity of ergosterol produced throughout the SSF of SFC, SBC and RSC, without the linseed oil enrichment (Fig. 1), it stands that the presence of linseed oil in the SSF mixture improved the fungus growth by $2.6,3.1$ and 3.8-fold, respectively. Similar Results were previously observed by Jang et al. (2005), which obtained the highest biomass yield of M. alpina ATCC 32222 when the basal medium was supplemented with $1 \%$ of linseed oil.

Fig. 5 shows the lipids content in the unfermented and fermented SFC, SBC and RSC supplemented with linseed oil. Compared to the unfermented solids, SSF of RSC led to an increase of lipids content of $43 \%$, while the SSF of SBC and SFC did not increased the lipid content. Similarly, the SSF of the brewery waste supplemented with linseed oil using different strains of Mortierella also increased the lipid production, achieving a maximum increase of $21 \%$ with regard to the unfermented substrate (Jacobs et al., 2009). During SSF, the lipids synthesis is affected by $\mathrm{C}$ and $\mathrm{N}$ availability in the substrates and, when $\mathrm{N}$ is lacking, the metabolism of oleaginous fungi changes to the accumulation of lipids (Jacobs et al., 2009; Mamani et al., 2019). Therefore, the different composition of oilcake could influence the accumulation of lipids by M. alpina. In the case of SFC supplemented with $10 \%$ of linseed oil, Jacobs et al. (2010) also observed a decrease in lipids content after the SSF using different strains of Mortierella.

The production of PUFAs by SSF of SFC, SBC and RSC supplemented with linseed oil is showed in Table 3. The total PUFAS only increased in SSF of RSC, in the same form that lipids content. Jang et al. (2005) observed that in SSF of rice bran with M. alpina ATCC 32222, the addition of $1 \%$ soybean oil and $1 \%$ of linseed oil to the substrate increased the total PUFAs production. Furthermore, the content of DHA significantly increased after SSF of the three substrates supplemented with linseed oil. In this case, the ALA must have been desaturated to DHA, indicating that the $\Delta 6$ and $\Delta 5$ desaturases were not inhibited during SSF.

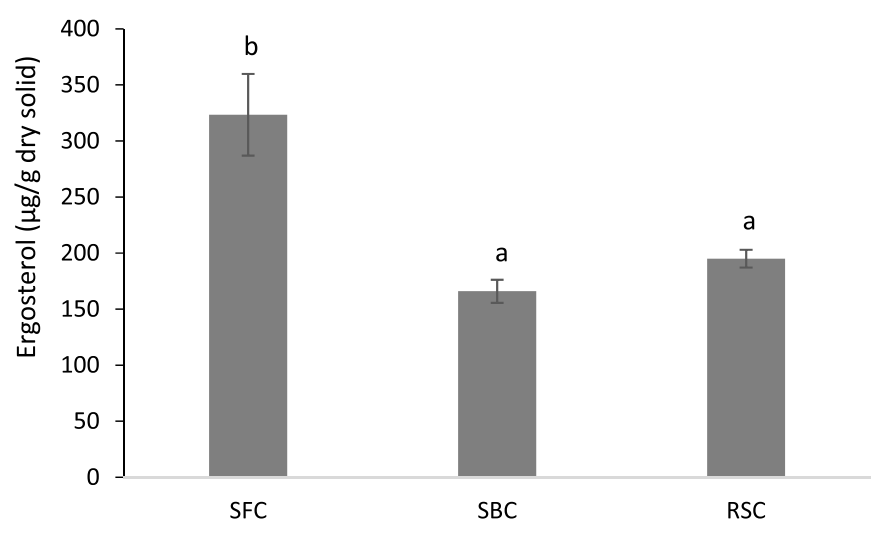

Fig. 4. Fungal biomass estimation, after 7 days of SSF by M. alpina of oilseed cakes (sunflower cake, SFC; soybean cake, SBC; rapeseed cake, RSC) supplemented with mineral salts and linseed oil ( $\mu$ g ergosterol/g dry solid). The Results represent the average of two independent experiments and error bars represent the standard deviation (SD). Different letters above each bar indicate a significant effect of the oilseed cake (Tukey's test; $\mathrm{P}<0.05$ ).

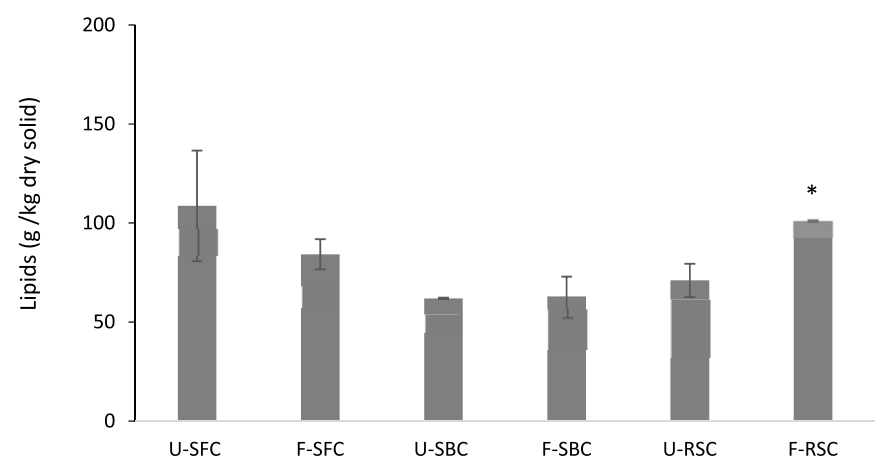

Fig. 5. Lipids content of unfermented (U) and fermented (F) substrates (sunflower cake, SFC; soybean cake, SBC; rapeseed cake, RSC; and linseed cake, LSC) supplemented with mineral salts and linseed oil by $M$. alpina Peyronel 9412 ( $\mathrm{g} / \mathrm{g}$ ds). The Results represent the average of two independent experiments and error bars represent the standard deviation (SD). *denotes significant differences between unfermented and fermented solid (Tukey's test; $\mathrm{P}<0.05$ ).

Table 3

PUFAs content of sunflower cake (SFC), soybean cake (SBC), and rapeseed cake (RSC) before and after SSF by M. alpina supplemented with linseed oil and mineral salts (mg PUFA/g dry solid).

\begin{tabular}{llllll}
\hline Substrate & LA & GLA & ALA & DHA & Total PUFAs \\
\hline U-SFC & $28 \pm 5$ & ND & $49 \pm 11$ & ND & $77 \pm 16$ \\
F-SFC & $24 \pm 1$ & ND & $37 \pm 4$ & $0.17 \pm$ & $61 \pm 5$ \\
& & & & $0.02^{*}$ & \\
U-SBC & $23 \pm 8$ & ND & $39 \pm 17$ & ND & $63 \pm 25$ \\
F-SBC & $16.74 \pm$ & ND & $29.27 \pm$ & $0.17 \pm 0.01$ & $46.25 \pm 0.14$ \\
& 0.05 & & 0.06 & & \\
U-RSC & $18.0 \pm 0.2$ & ND & $29 \pm 1$ & ND & $46 \pm 2$ \\
F-RSC & $22 \pm 1^{*}$ & ND & $36 \pm 1^{*}$ & $0.33 \pm$ & $60 \pm 2^{*}$ \\
& & & & $0.05^{*}$ & \\
\hline
\end{tabular}

Mean \pm SD. $n=2$. Means in the same column that do not share the same alphabetic superscript show significant difference at 5\% level according to Tukey's test.

ND: not detectable; PUFAs: polyunsaturated fatty acids; LA: linoleic acid; GLA: $\gamma$-linolenic acid; ALA: $\alpha$-linolenic acid; DHA: docosahexaenoic acid; SFC: sunflower cake; SBC: soybean cake, RSC: rapeseed cake).

In the case of RSC, LA, GLA and ALA also increased after the SSF by $26.5 \%, 25 \%$ and $20.3 \%$. Thus, the supplementation of RSC with linseed oil is a suitable strategy to increase the PUFAs production.

\subsection{The relation between substrates and their bioenrichment by M. alpina}

PCA analysis relating the unfermented and the fermented solids with the variables analyzed, allowed to obtain a reduced number of linear combinations of the 8 variables analyzed which explained most of the data variability (Fig. 6). Thus, two principal components (PC) explained $87 \%$ of the variability in the original data. The PC1 explained $71.4 \%$ of the variance and was positively correlated with lipids, PUFAs, LA, ALA and DHA contents, and it was negatively correlated with protein and GLA. The PC2 explained $15.7 \%$ of variance, which was positively correlated with ergosterol and protein contents and negatively correlated with GLA. The PCA analysis grouped the unfermented and fermented solids into three groups (Fig. 6). The unfermented and fermented whole-linseed are located together with the positive values of PC1, reflecting the highest content of lipids and total PUFAs of these solids. The unfermented and fermented oilseed cakes were correlated with protein content at the left of Fig. 6, as these substrates had a higher protein content. The third group was located in the positive zone of PC2 (Fig. 6), characterized by the higher content of ergosterol. This group was constituted by the fermented oilseed cakes supplemented with linseed oil, which induced the production of fungal biomass. 


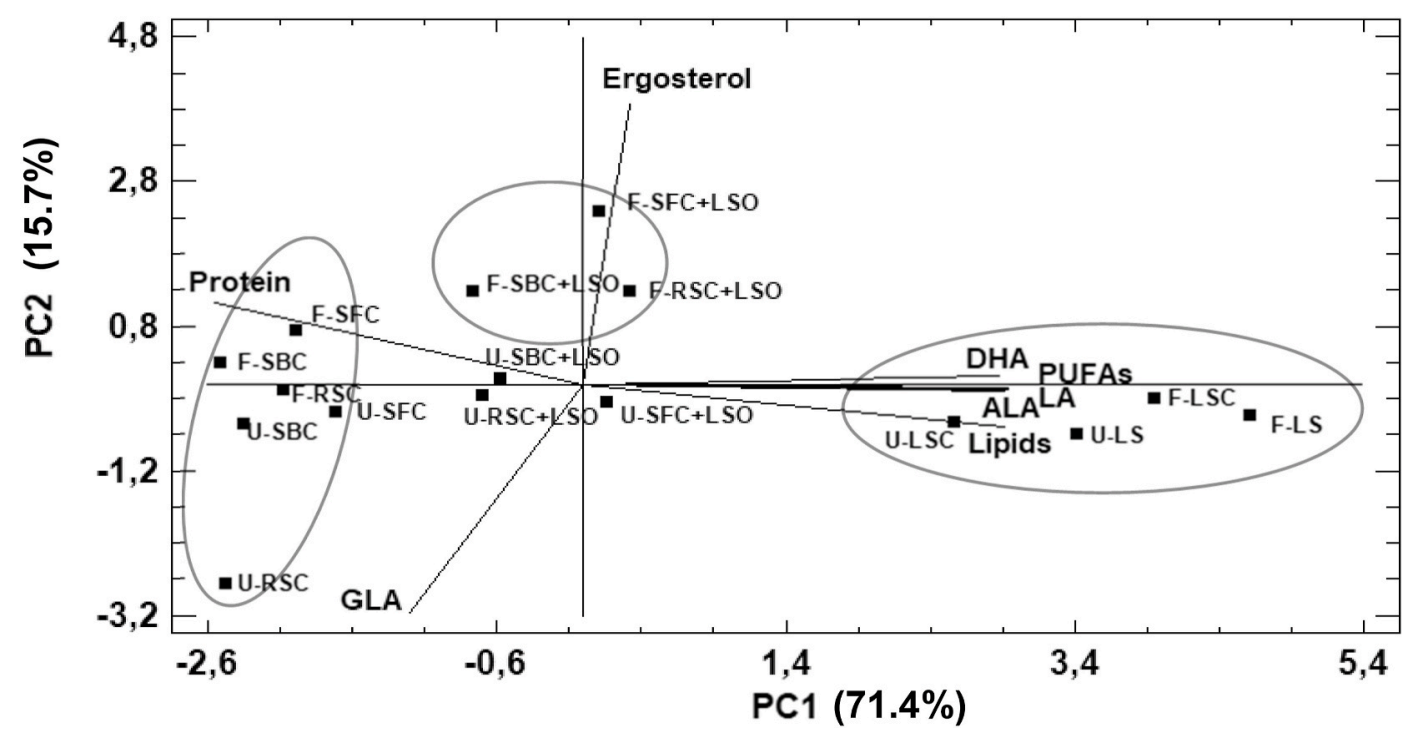

Fig. 6. Biplot representation of variables and scores of the unfermented and fermented solids (unfermented, U; fermented F; sunflower cake, SFC; soybean cake, SBC; rapeseed cake, RSC; and linseed cake, LSC; polyunsaturated fatty acids, PUFAs; linoleic acid, LA; $\gamma$-linolenic acid, GLA; $\alpha$-linolenic acid, ALA; docosahexaenoic acid; DHA).

\section{Conclusion}

This study showed the potential utilization of the fungus $M$. alpina Peyronel MUM 9412 to increase the nutritional value of oilseed cakes by SSF. The growth of this strain led to a significant increment of total PUFAs content and more specifically LA, ALA and DHA. The fermentation of whole-linseed, before linseed oil extraction, was a suitable strategy to increase its $\omega-3$ fatty acids content. In the same process, the protein content of whole-linseed and linseed cake also increased. The utilization of linseed oil as a supplement to SSF of RSC was positive for fungal growth and production of protein and PUFAs.

\section{CRediT authorship contribution statement}

Marta Ferreira: Methodology, Formal analysis, Investigation, Writing - original draft, Visualization. Helena Fernandes: Formal analysis, Investigation, Writing - review \& editing. Helena Peres: Writing - review \& editing, Resources, Project administration, Funding acquisition. Aires Oliva-Teles: Writing - review \& editing, Resources, Project administration, Funding acquisition. Isabel Belo: Writing - review \& editing, Resources, Project administration, Funding acquisition. José Manuel Salgado: Conceptualization, Investigation, Writing original draft, Visualization, Supervision.

\section{Declaration of competing interest}

The authors declare that they have no known competing financial interests or personal relationships that could have appeared to influence the work reported in this paper.

\section{Acknowledgments}

José Manuel Salgado was supported by grant CEB/N2020 - INV/01/ 2016 from Project "BIOTECNORTE - Underpinning Biotechnology to foster the north of Portugal bioeconomy" (NORTE-01-0145-FEDER000004). This work was supported by the project "Development of innovative sustainable protein and omega- 3 rich feedstuffs for aquafeeds, from local agro-industrial by-products", reference POCI-01-0145FEDER-030377, funded by European Regional Development Fund (ERDF). This study was supported by the Portuguese Foundation for Science and Technology (FCT) under the scope of the strategic funding of UID/BIO/04469/2019 unit and BioTecNorte operation (NORTE-010145-FEDER-000004) funded by the European Regional Development Fund under the scope of Norte2020 - Programa Operacional Regional do Norte.

\section{References}

Abedi, E., \& Sahari, M. A. (2014). Long-chain polyunsaturated fatty acid sources and evaluation of their nutritional and functional properties. Food Sciences and Nutrition, 2(5), 443-463. https://doi.org/10.1002/fsn3.121.

Ahmad, S., Kamran, Z., \& Koutoulis, K. C. (2017). Supplemental linseed on egg production. In Egg innovation and strategies for improvement (pp. 349-363). https:// doi.org/10.1016/B978-0-12-800879-9/00033-0.

Aita, B., Spannemberg, S., Kuhn, R., \& Marcio, M. (2018). Production of polyunsaturated fatty acids by solid state fermentation. In A. Kuila, \& V. Sharma (Eds.), Principles and applications of fermentation Technology (pp. 217-237). Scrivener Publishing LLC.

Araujo, P., Nguyen, T., Frøyland, L., Wang, J., \& Kang, J. X. (2008). Evaluation of a rapid method for the quantitative analysis of fatty acids in various matrices. Journal of Chromatography A, 1212(1-2), 106-113. https://doi.org/10.1016/j. chroma.2008.10.006.

Banaszkiewicz, T. (2011). Nutritional value of soybean meal. In H. El-Shemy (Ed.), Soybean and nutrition (pp. 1-21). InTech.

Béligon, V., Christophe, G., Fontanille, P., \& Larroche, C. (2016). Microbial lipids as potential source to food supplements. Current Opinion in Food Science, 7, 35-42. https://doi.org/10.1016/j.cofs.2015.10.002.

Bellou, S., Triantaphyllidou, I. E., Aggeli, D., Elazzazy, A. M., Baeshen, M. N., \& Aggelis, G. (2016). Microbial oils as food additives: Recent approaches for improving microbial oil production and its polyunsaturated fatty acid content. Current Opinion in Biotechnology, 37, 24-35. https://doi.org/10.1016/j.copbio.2015.09.005.

Cantrell, K. B., \& Walker, T. H. (2009). Influence of temperature on growth and peak oil biosynthesis in a carbon-limited medium by pythium irregulare. Journal of the American Oil Chemists' Society, 86, 791-797. https://doi.org/10.1007/s11746-0091409-0.

Certik, M., \& Shimizu, S. (1999). Biosynthesis and regulation of microbial polyunsaturated fatty acid production. Journal of Bioscience and Bioengineering, 87 (1), 1-14. https://doi.org/10.1016/S1389-1723(99)80001-2.

Conti, E., Stredansky, M., Stredanska, S., \& Zanetti, F. (2001). $\gamma$-Linolenic acid production by solid-state fermentation of Mucorales strains on cereals. Bioresource Technology, 76(3), 283-286. https://doi.org/10.1016/S0960-8524(00)00097-3.

Dulf, F. V., Vodnar, D. C., Dulf, E. H., Diaconeasa, Z., \& Socaciu, C. (2018). Liberation and recovery of phenolic antioxidants and lipids in chokeberry (Aronia melanocarpa) pomace by solid-state bioprocessing using Aspergillus Niger and Rhizopus oligosporus strains. Lebensmittel-Wissenschaft und -Technologie- Food Science and Technology, 87, 241-249. https://doi.org/10.1016/j.lwt.2017.08.084.

Dyal, S. D., \& Narine, S. S. (2005). Implications for the use of Mortierella fungi in the industrial production of essential fatty acids. Food Research International, 38(4), 445-467. https://doi.org/10.1016/j.foodres.2004.11.002.

FAO. (2018). Oilcrops, oils and meals in Food outlook. July 2018.

Fernandes, H., Salgado, J. M., Martins, N., Peres, H., Oliva-Teles, A., \& Belo, I. (2019). Sequential bioprocessing of Ulva rigida to produce lignocellulolytic enzymes and to improve its nutritional value as aquaculture feed. Bioresource Technology, 281, 277-285. https://doi.org/10.1016/j.biortech.2019.02.068. December 2018. 
Fontani, G., Corradeschi, F., Felici, A., Alfatti, F., Migliorini, S., \& Lodi, L. (2005). Cognitive and physiological effects of Omega-3 polyunsaturated fatty acid supplementation in healthy subjects. European Journal of Clinical Investigation, 35, 691-699. https://doi.org/10.1111/j.1365-2362.2005.01570.x.

Gutiérrez, C., Rubilar, M., Jara, C., Verdugo, M., Sineiro, J., \& Shene, C. (2010). Flaxseed and flaxseed cake as a source of compounds for food industry. Journal of Soil Science and Plant Nutrition, 10(4), 454-463. https://doi.org/10.4067/S071895162010000200006.

Ivanov, D., Lević, J., \& Sredanović, S. (2010). Fatty acid composition of various soybean products. Food and Feed Research, 2, 65-70.

Jacobs, A., Botha, A., Reddy, J. K., \& Van Zyl, W. H. (2010). Sunflower press cake as a substrate for eicosapentaenoic acid production by representatives of the genus mortierella. BioResources, 5(2), 1232-1243. https://doi.org/10.15376/ biores.5.2.1232-1243.

Jacobs, A., Botha, A., \& Van Zyl, W. H. (2009). The production of eicosapentaenoic acid by representatives of the genus Mortierella grown on brewers' spent grain. Biologia, 64(5), 871-876. https://doi.org/10.2478/s11756-009-0152-1.

Jang, H.-D., Lin, Y.-Y., \& Yang, S.-S. (2000). Polyunsaturated fatty acid production with Mortierella alpina by solid substrate fermentation. Botanical Bulletin of Academia Sinica, 41(1), 41-48. https://doi.org/10.7016/BBAS.200001.0041.

Jang, H.-der, Lin, Y., \& Yang, S. (2005). Effect of culture media and conditions on polyunsaturated fatty acids production by Mortierella alpina. Bioresource Technology, 96, 1633-1644. https://doi.org/10.1016/j.biortech.2004.12.027.

Jang, H. Der, \& Yang, S. S. (2008). Polyunsaturated fatty acids production with a solidstate column reactor. Bioresource Technology, 99(14), 6181-6189. https://doi.org/ 10.1016/j.biortech.2007.12.024.

Jiménez-Peñalver, P., Gea, T., Sánchez, A., \& Font, X. (2016). Production of sophorolipids from winterization oil cake by solid-state fermentation: Optimization, monitoring and effect of mixing. Biochemical Engineering Journal, 115, 93-100. https://doi.org/10.1016/j.bej.2016.08.006.

Kaczmarek, P., Korniewicz, D., Lipiński, K., \& Mazur, M. (2017). Chemical composition of rapeseed products and their use in pig nutrition. Polish Journal of Natural Sciences, 31(4), 545-562.

Koritala, S., Hesseltine, C. W., Pryde, E. H., \& Mounts, T. L. (1987). Biochemical modification of fats by microorganisms: A preliminary survey. Journal of the American Oil Chemists' Society, 64(4), 509-513. https://doi.org/10.1007/ BF02636384.

Leite, P., Salgado, J. M., Venâncio, A., Domínguez, J. M., \& Belo, I. (2016). Ultrasounds pretreatment of olive pomace to improve xylanase and cellulase production by solidstate fermentation. Bioresource Technology, 214, 737-746. https://doi.org/10.1016/ j.biortech.2016.05.028.

Li, D., \& Hu, X. (2009). Fish and its multiple human health effects in times of threat to sustainability and affordability: Are there alternatives? Asia Pacific Journal of Clinical Nutrition, 18, 553-563.

Lu, M. Y., Maddox, I. S., \& Brooks, J. D. (1998). Application of a multi-layer packed-bed reactor to citric acid production in solid-state fermentation using Aspergillus Niger. Process Biochemistry, 33(2), 117-123. https://doi.org/10.1016/S0032-9592(97) 00037-X.

Mamani, L. D. G., Magalhães, A. I., Ruan, Z., Carvalho, J. C. de, \& Soccol, C. R. (2019). Industrial production, patent landscape, and market trends of arachidonic acid-rich oil of Mortierella alpina. Biotechnology Research and Innovation, 3(1), 103-119. https://doi.org/10.1016/j.biori.2019.02.002.

Moura, S., Ferreira, D., Lucas, E., Peixoto, T., Harry, V., Junior, B., \& Fortaleza, D. S. (2015). Sunflower cake in diets for lambs: Intake, digestibility, nitrogen balance and rumen parameters. Semina: Ciências Agrárias, 36, 2247-2258. https://doi.org/ 10.5433/1679-0359.2015v36n3Supl1p2247.
Ochsenreither, K., Glück, C., Stressler, T., Fischer, L., \& Syldatk, C. (2016). Production strategies and applications of microbial single cell oils. Frontiers in Microbiology, 7. https://doi.org/10.3389/fmicb.2016.01539. OCT.

Pedroche, J. (2015). Utilization of sunflower proteins. In E. Martínez-Force, N. Turgut Dunford, \& J. Salas (Eds.), Sunflower: Chemistry, production, processing, and utilization (pp. 395-439). https://doi.org/10.1016/B978-1-893997-94-3.50019-2.

Ramachandran, S., Kumar, S., Larroche, C., Ricardo, C., \& Pandey, A. (2007). Oil cakes and their biotechnological applications - a review. Bioresource Technology, 98(10), 2000-2009. https://doi.org/10.1016/j.biortech.2006.08.002.

Ratledge, C. (2004). Fatty acid biosynthesis in microorganisms being used for Single Cell Oil production. Biochimie, 86(11), 807-815. https://doi.org/10.1016/j. biochi.2004.09.017.

Sakuradani, E., Ando, A., \& Ogawa, J. (2009). Improved production of various polyunsaturated fatty acids through filamentous fungus Mortierella alpina breeding. Applied Microbiology and Biotechnology, 84, 1-10. https://doi.org/10.1007/s00253009-2076-7.

Salim, A. A., Grbavčić, S., Šekuljica, N., Stefanović, A., Jakovetić Tanasković, S., Luković, N., \& Knežević-Jugović, Z. (2017). Production of enzymes by a newly isolated Bacillus sp. TMF-1 in solid state fermentation on agricultural by-products: The evaluation of substrate pretreatment methods. Bioresource Technology, 228, 193-200. https://doi.org/10.1016/j.biortech.2016.12.081.

Sheih, I. C., Fang, T. J., Wu, T. K., \& Chen, R. Y. (2014). Effects of fermentation on antioxidant properties and phytochemical composition of soy germ. Journal of the Science of Food and Agriculture, 94(15), 3163-3170. https://doi.org/10.1002/ jsfa.6666.

Simopoulos, A. P. (1999). Essential fatty acids in health and chronic disease. American Journal of Clinical Nutrition, 70, 560-569.

Singh, A., \& Ward, O. (1997). Production of high yields of arachidonic acid in a fed-batch system by Mortierella alpina ATCC 32222. Applied Microbiology and Biotechnology, 48, 1-5. https://doi.org/10.1007/s002530051005.

Stressler, T., Eisele, T., Rost, J., Haunschild, E. M., Kuhn, A., \& Fischer, L. (2013). Production of polyunsaturated fatty acids by Mortierella alpina using submerse and solid state fermentation. Chemie Ingenieur Technik, 85(3), 318-322. https://doi.org/ 10.1002/cite.201200094.

Teh, S., \& Bekhit, A. E. A. (2015). Utilization of oilseed cakes for human nutrition and health benefits. In K. Hakeem, M. Jawaid, \& O. Alothman (Eds.), Agricultural biomass based potential materials (pp. 191-229). https://doi.org/10.1007/978-3-319-138473.

Thomas, L., Larroche, C., \& Pandey, A. (2013). Current developments in solid-state fermentation. Biochemical Engineering Journal, 81, 146-161. https://doi.org/ 10.1016/j.bej.2013.10.013.

Yang, H., Tong, J., Lee, C. W., Ha, S., Eom, S. H., \& Im, Y. J. (2015). Structural mechanism of ergosterol regulation by fungal sterol transcription factor Upc2. Nature Communications, 6(1), 1-13. https://doi.org/10.1038/ncomms7129.

Yang, S., \& Zhang, H. (2016). Enhanced polyunsaturated fatty acids production in Mortierella alpina by SSF and the enrichment in chicken breasts. Food \& Nutrition Research, 60, 1-8. https://doi.org/10.3402/fnr.v60.30842.

Yu, Y., Li, T., Wu, N., Ren, L., Jiang, L., Ji, X., \& Huang, H. (2016). Mechanism of arachidonic acid accumulation during aging in mortierella alpina: A large-scale label-free comparative proteomics study. Journal of Agricultural and Food Chemistry, 64(47), 9124-9134. https://doi.org/10.1021/acs.jafc.6b03284.

Zhang, J., \& Hu, B. (2012). Solid-state fermentation of Mortierella isabellina for lipid production from soybean hull. Applied Biochemistry and Biotechnology, 166(4), 1034-1046. https://doi.org/10.1007/s12010-011-9491-9. 